\title{
Why coronary artery bypass grafting remains the standard of care for patients with complex, multivessel coronary artery disease
}

\author{
Joseph F. Sabik III, MD
}

\footnotetext{
From the Department of Thoracic and Cardiovascular Surgery, Cleveland Clinic, Cleveland, Ohio. This work was funded by the Cleveland Clinic Department of Thoracic and Cardiovascular Surgery. Disclosures: J.S. is the North American principal investigator for an Abbott Laboratories-sponsored left main coronary disease randomized trial, is on the Society of Thoracic Surgeons Board of Directors, and is on the scientific advisory board of Medtronic.

Received for publication Aug 1, 2016; accepted for publication Aug 3, 2016; available ahead of print Aug 26, 2016.

Address for reprints: Joseph F. Sabik III, MD, Department of Thoracic and Cardiovascular Surgery, Cleveland Clinic, 9500 Euclid Ave, Desk J-450, Cleveland, OH 44195 (E-mail: sabikj@ccf.org).

J Thorac Cardiovasc Surg 2016;152:1227-8

$0022-5223 / \$ 36.00$

Copyright (C) 2016 by The American Association for Thoracic Surgery http://dx.doi.org/10.1016/j.jtcvs.2016.08.002
}

In the article by Mack and colleagues, ${ }^{1}$ the authors review the Synergy Between Percutaneous Coronary Intervention With Taxus and Cardiac Surgery (SYNTAX) trial to demonstrate why coronary artery bypass grafting (CABG) and not percutaneous coronary intervention (PCI) is the best revascularization strategy for patients with complex coronary artery disease (CAD). They focus on several findings from SYNTAX. First, myocardial infarctions (MIs) are more prevalent in patients undergoing PCI, leading to a 10-fold higher incidence of cardiac death due to MI. Second, incomplete revascularization is greater in patients undergoing PCI. Third, incomplete revascularization is an independent predictor of major adverse cardiac and cerebrovascular events after PCI, but not after CABG. These observations drive the finding that by 5 years, CABG is superior to PCI due to both less repeat revascularization and a lower incidence of death, stroke, and MI.

The fact that more MIs and incomplete revascularizations occur after PCI was not a new finding in SYNTAX. In the Bypass Angioplasty Revascularization Investigation 2 Diabetes (BARI 2D) trial, CABG decreased the composite end point of death, MI, and stroke at 5 years compared with medical therapy, mostly due to a reduction in MIs $(10 \%$ vs $17.6 \% ; P=.003){ }^{2}$ PCI did not. Recently, the superiority of CABG over PCI in decreasing MIs after revascularization was demonstrated in the Future Revascularization Evaluation in Patients With Diabetes Mellitus: Optimal Management of Multivessel Disease (FREEDOM) trial, a study of CABG versus PCI in diabetic patients with multivessel CAD. At 5 years, MIs occurred in $6.0 \%$ of patients undergoing CABG and in $13.9 \%$ of those receiving PCI $(P<.001)$.

Similarly, more incomplete revascularization has been observed after PCI than after CABG. This difference is directly proportional to CAD complexity, resulting in more residual ischemia (RI) in PCI patients with complex CAD. ${ }^{4}$ The relationship between the degree of RI and

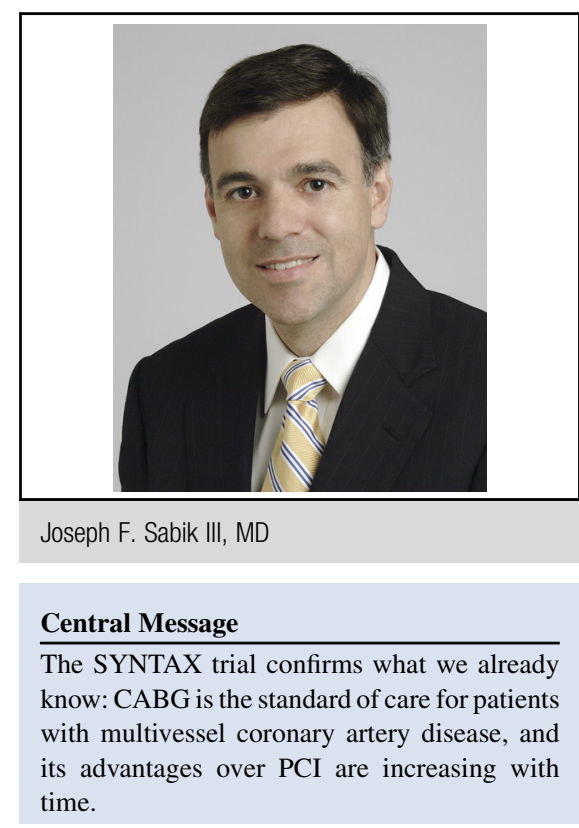

See Article page 1237.

worse long-term outcomes is well known. In the Clinical Outcomes Utilizing Revascularization and Aggressive Drug Evaluation (COURAGE) trial, death and MI were directly related to RI, and an analysis of the Acute Catheterization and Urgent Intervention Triage Strategy (ACUITY) trial demonstrated that as RI (represented by the residual SYNTAX score) increases, so too does the likelihood of cardiac death, all-cause death, MI, and repeat revascularization. ${ }^{5,6}$

Why is CABG more effective than PCI in treating complex CAD? The answer is likely the inherent differences in the 2 revascularization techniques. Yock and colleagues ${ }^{7}$ wrote in their analysis of the BARI 2D trial results that "even if target lesion restenosis were to be completely eliminated, $\mathrm{CABG}$ would remain more effective than primary PCI stenting." Unlike PCI, which treats only the stenosis present at the time of revascularization, CABG treats both the current stenosis and any future stenosis that develops proximal to the distal anastomoses. It is not surprising that Cutlip and colleagues ${ }^{8}$ observed that during the first year after PCI, repeat revascularization is due to a target lesion event, but after 1 year, it is likely due to a nontarget lesion event. In addition, whether a vessel is totally 
occluded or the stenosis is complex, performing PCI may be difficult, dangerous, and even impossible, leading to incomplete revascularization and residual ischemia. Performing $\mathrm{CABG}$ to these vessels is no more difficult than for an isolated, noncomplex stenosis.

This review of SYNTAX confirms what we already know: CABG is the standard of care for patients with multivessel CAD. The authors should be congratulated for continuing this discussion and advocating for patients with complex CAD to receive the best revascularization therapy.

\section{References}

1. Mack M, Baumgarten H, Lytle B. Why surgery won the SYNTAX trial and why it matters. J Thorac Cardiovasc Surg. 2016;152:1237-40.

2. Frye RL, August P, Brooks MM, Hardison RM, Kelsey SF, MacGregor JM, et al. A randomized trial of therapies for type 2 diabetes and coronary artery disease. $N$ Engl J Med. 2009;360:2503-15.
3. Farkouh ME, Domanski M, Sleeper LA, Siami FS, Dangas G, Mack M, et al. Strategies for multivessel revascularization in patients with diabetes. New Engl J Med. 2012;367:2375-84

4. Capodanno D, Capranzano P, Di Salvo ME, Caggegi A, Tomasello D, Cincotta G, et al. Usefulness of SYNTAX score to select patients with left main coronary artery disease to be treated with coronary artery bypass graft. JACC Cardiovasc Interv. 2009;2:731-8.

5. Shaw LJ, Berman DS, Maron DJ, Mancini GB, Hayes SW, Hartigan PM, et al. Optimal medical therapy with or without percutaneous coronary intervention to reduce ischemic burden: results from the Clinical Outcomes Utilizing Revascularization and Aggressive Drug Evaluation (COURAGE) trial nuclear substudy. Circulation. 2008;117:1283-91.

6. Genereux P, Palmerini T, Caixeta A, Rosner G, Green P, Dressler O, et al. Quantification and impact of untreated coronary artery disease after percutaneous coronary intervention: the residual SYNTAX (Synergy Between PCI with Taxus and Cardiac Surgery) score. J Am Coll Cardiol. 2012;59:2165-74.

7. Yock CA, Boothroyd DB, Owens DK, Garber AM, Hlatky MA. Cost-effectiveness of bypass surgery versus stenting in patients with multivessel coronary artery disease. Am J Med. 2003;115:382-9.

8. Cutlip DE, Chhabra AG, Baim DS, Chauhan MS, Marulkar S, Massaro J, et al. Beyond restenosis: five-year clinical outcomes from second-generation coronary stent trials. Circulation. 2004;110:1226-30.

Access to The Journal of Thoracic and Cardiovascular Surgery Online is reserved for print subscribers!

Full-text access to The Journal of Thoracic and Cardiovascular Surgery Online is available for all print subscribers. To activate your individual online subscription, please visit The Journal of Thoracic and Cardiovascular Surgery Online, point your browser to http://www.mosby.com/jtcvs, follow the prompts to activate your online access, and follow the instructions. To activate your account, you will need your subscriber account number, which you can find on your mailing label (note: the number of digits in your subscriber account number varies from 6 to 10 ). See the example below in which the subscriber account number has been circled:

\section{Sample mailing label}

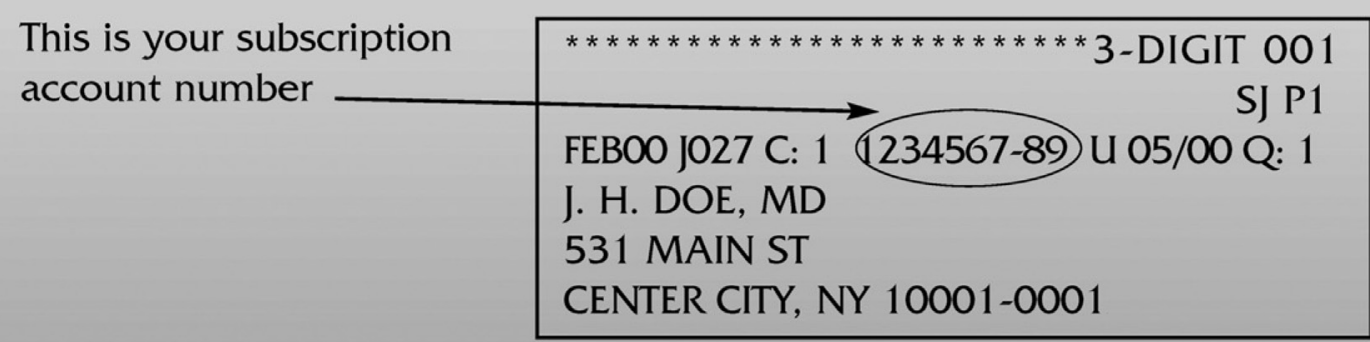

Personal subscriptions to The Journal of Thoracic and Cardiovascular Surgery Online are for individual use only and may not be transferred. Use of The Journal of Thoracic and Cardiovascular Surgery Online is subject to agreement to the terms and conditions as indicated online. 